\title{
Remdesivir in COVID-19 management: availability and relevance to low- and middle-income countries
}

\author{
Sugat Adhikari ${ }^{1} \cdot$ Sitaram Khadka ${ }^{2,3,5}$ (1) Sadhana Dahal ${ }^{3} \cdot$ Dhan Bahadur Shrestha ${ }^{4} \cdot$ Janak Shahi $^{5} \cdot$ Yogesh Bajgain $^{5}$
}

Published online: 28 October 2020

(c) Springer Nature Switzerland AG 2020

\section{Background}

Coronavirus disease 2019 (COVID-19) comprises a spectrum of pathologies, including serious respiratory illness such as pneumonia and lung failure, and is caused by severe acute respiratory syndrome coronavirus-2 (SARS-CoV-2) [1]. Treatment guidelines and protocols for the management of COVID-19 have been prepared globally by various healthcare organizations and regulatory agencies; however, to date, no specific treatment option has been proven to cure COVID-19.

On 1 May 2020, the US FDA granted an Emergency Use Authorization for remdesivir [2], a nucleotide analog prodrug that inhibits viral RNA polymerase. Having previously undergone research in the treatment of Ebola, the focus has recently been on the use of remdesivir in the treatment of COVID-19 [3].

With COVID-19 cases in Nepal rising to 70,614 as of 25 September 2020, with the death of 459 patients [4], Nepal is seeing a steep rise in cases. A major share of the population is of low socioeconomic status, and with no production of remdesivir within Nepal, the relevance and significance of the use of this drug to treat COVID-19 in that country, as well as in other low- and middle-income countries (LMICs), is questionable.

Sitaram Khadka

sitaramkhadka5693@gmail.com;

sitaram.khadka@naihs.edu.np

1 Nishtar Medical University, Multan, Pakistan

2 Shree Birendra Hospital, Kathmandu, Nepal

3 Nepalese Army Institute of Health Sciences, Kathmandu, Nepal

4 Mangalbare Hospital, Morang, Nepal

5 Punjab University College of Pharmacy, University of the Punjab, Lahore, Pakistan

\section{Clinical evidence}

In common with most antiviral drugs, remdesivir is more efficacious when administered early in the course of the disease than when administered in the later critical stage [5]. With its broad spectrum of activity, remdesivir inhibits RNA-dependent RNA polymerases and causes arrest in RNA synthesis, most probably by delaying RNA chain termination [6].

Several clinical trials have been conducted to determine the efficacy of remdesivir in COVID-19 patients. Studies have suggested a shortened course of treatment, a reduction in viral load, and clinical efficacy when the drug is administered early in the course of the disease. The significant clinical improvement in respiratory status (68\% of 61 patients) and shortening of the disease course was reported in the study by Grein et al. [7]. These results are supported by those of a larger study $(n=1026)$ by Beigel et al., with the median recovery time being shortened from 15 days with placebo to 10 days with remdesivir, but with no significant reduction in mortality rate [8]. The study conducted by Goldman et al. $(n=397)$ showed clinical improvement of $\geq 2$ points on a 7 -point ordinal scale in $64 \%$ and $54 \%$ of patients receiving a 5- or 10-day regimen of remdesivir, respectively, with those receiving 10 days of treatment being at a clinically worse status at the beginning of the trial [9]. Remdesivir significantly reduced viral load in a study conducted in China, but the study was terminated early as COVID-19 became controlled during the early stages of the trial and no new patients were available for randomization [10]. Overall, the efficacy of remdesivir in the treatment of COVID-19 is currently questionable as the main purpose of a therapeutic agent during the COVID-19 pandemic is to reduce mortality, not to decrease the length of hospital stay [11].

The adverse effects associated with remdesivir include hypoalbuminemia, constipation, anemia, hypokalemia, increased bilirubin, thrombocytopenia, and acute respiratory 
failure $[9,10]$. The study by Beigel et al. suggested that adverse effects did not differ significantly between placebo and remdesivir [8]. Forty-four clinical trials of remdesivir for COVID-19 are currently registered [12]. Studies with larger populations, and which also compare the efficacy of remdesivir with that of other antiviral drugs, are needed to confirm the relevance of remdesivir in treating COVID-19.

\section{Cost and availability}

Gilead Sciences stated that by April 2020 they would have produced enough remdesivir for 140,000 courses of treatment, and that most of this will be supplied to the US market [13]. Beximco Pharmaceuticals Limited in Bangladesh is the first South-Asian company to start the production of a generic version of remdesivir. Gilead's recent agreements with India's Cipla and Jubilant Life Sciences, as well as with Pakistan's Ferozsons Laboratories, will increase the production of remdesivir in this region. Substantial amounts of the drug need to be distributed. Given that Pakistan had 309,581 cases and India had 5,908,748 cases of COVID-19 as at 25 September 2020, the supply of remdesivir to Nepal and other LMICs will certainly be limited.

In the USA, the official cost of remdesivir is US $\$ 520$ per vial for those with private insurance and US\$390 per vial for those without insurance [14]. The required dose of remdesivir is two vials on the first day and one vial per day for the remaining course of the treatment. This brings the cost to US\$2340-3120 for a 5-day course and US\$4290-5720 for a 10-day course. Cipla International has distributed the drug at a price of US\$53.34 per vial in India, although a higher price of up to US\$818 per vial has been reported due to insufficient production and black marketing $[15,16]$. Heavily criticized for its initial cost of US\$84,000 for one course of sofosbuvir [17], the pricing policy of Gilead has been considered predatory by some. At current costs, the financial burden of a course of remdesivir might be unbearable for many patients. With the economy falling apart, the next logical question is will Nepal, as well as other LMICs, be able bear the costs of such medications, even if the availability of these medications can be established?

\section{Use in low- and middle-income countries}

Remdesivir appears to be more potent when administered early in the course of disease [5]. This makes it difficult to select which patients are to be administered the drug, considering the uncertainty of progression of the disease and significant demographic variation. As a result, a large proportion of patients would require the drug, which is difficult to acquire and very expensive in LMICs such as Nepal. Thus, the use of remdesivir is relatively insignificant for routine treatment regimens to treat COVID-19 in LIMICs.

\section{Conclusion}

Currently, no therapies have established efficacy and safety for the management of COVID-19. Given the experimental phase of the management of the disease, the use of remdesivir has shown some positive results, and its compassionate use during the early stages of the disease is justified. Remdesivir may be a promising medication for COVID-19 but the results of well-designed clinical trials are necessary to clarify its effectiveness, tolerability, and safety. However, for LMICs such as Nepal, the use of remdesivir in the treatment of COVID-19 is currently insignificant due to its unavailability and the high acquisition cost of the drug, as well as the lack of evidence regarding its effects in reducing mortality. To make this drug relevant to COVID-19 management in LMICs, production should be commenced at the national level, followed by government implementation of price reduction strategies after its mass production.

\section{Declarations}

Funding None of the authors received any form of direct or indirect commercial financial incentives in relation to this manuscript.

Competing or conflicts of interest Sugat Adhikari, Sitaram Khadka, Sadhana Dahal, Dhan Bahadur Shrestha, Janak Shahi, and Yogesh Bajgain declare they have no competing interests in relation to the preparation of this manuscript.

Availability of data and materials Not applicable.

Code availability Not applicable.

Author contributions SA contributed to the concept and writing of the manuscript. SK, SD and DBS guided and reviewed the manuscript. JS and $\mathrm{YB}$ contributed to the literature search and assisted in writing the manuscript. All authors read and approved the manuscript.

\section{References}

1. Ahn DG, Shin HJ, Kim MH, et al. Current status of epidemiology, diagnosis, therapeutics, and vaccines for novel coronavirus disease 2019 (COVID-19). J Microbiol Biotechnol. 2020;30(3):313-24.

2. US FDA. Remdesivir EUA: letter of authorization. https://www. fda.gov/media/137564/download. Accessed 25 Sep 2020.

3. US FDA. Remdesivir EUA fact sheet for health care providers. https://www.fda.gov/media/137566/. Accessed 25 Sep 2020.

4. World Health Organization. Coronavirus (COVID-19). https:// covid19.who.int/. Accessed 25 Sep 2020.

5. European Medicines Agency. Summary on compassionate use: remdesivir Gilead. https://www.ema.europa.eu/en/documents/ other/summary-compassionate-use-remdesivir-gilead_en.pdf. Accessed 25 Sep 2020 
6. Gordon CJ, Tchesnokov EP, Feng JY, et al. The antiviral compound remdesivir potently inhibits RNA-dependent RNA polymerase from Middle East respiratory syndrome coronavirus. J Biol Chem. 2020;295(15):4773-9.

7. Grein J, Ohmagari N, Shin D, et al. Compassionate use of remdesivir for patients with severe Covid-19. N Engl J Med. 2020;382(24):2327-36.

8. Beigel JH, Tomashek KM, Dodd L, et al. Remdesivir for the treatment of Covid-19: final report. N Engl J Med. 2020. https://doi. org/10.1056/NEJMoa2007764 (Epub 8 Oct 2020).

9. Goldman JD, Lye DC, Hui DS, et al. Remdesivir for 5 or 10 days in patients with severe Covid-19. N Engl J Med. 2020. https://doi. org/10.1056/NEJMoa2015301 (Epub 27 May 2020).

10. Wang Y, Zhang D, Du G, et al. Remdesivir in adults with severe COVID-19: a randomised, double-blind, placebo-controlled, multicentre trial. Lancet. 2020;395(12036):1569-78.

11. Herper M. Inside the NIH's controversial decision to stop its big remdesivir study. STAT. https://www.statnews.com/2020/05/11/ inside-the-nihs-controversial-decision-to-stop-its-big-remdesivir -study/. Accessed 25 Sep 2020

12. US National Library of Medicine. ClinicalTrials.gov. https:// clinicaltrials.gov/ct2/results?term $=$ Remdesivir\&cond=COVID
$+19 \&$ Search $=$ Apply\&age_v $=\&$ gndr $=\&$ type $=\& r s l t=$. Accessed 25 Sep 2020.

13. O'Day D. An open letter from our chairman \& CEO. Gilead. https ://stories.gilead.com//articles/an-open-letter-from-our-chairmanand-ceo-april-29. Accessed 25 Sep 2020.

14. Inserro A. Gilead Sciences sets US price for COVID-19 drug at $\$ 2340$ to $\$ 3120$ based on insurance. AJMC. https://www.ajmc. $\mathrm{com} /$ view/gilead-sciences-sets-us-price-for-covid19-drug-at2340-to-3120-based-on-insurance. Accessed 30 Sep 2020.

15. Mitra A, Cavale S. India's Cipla prices its generic remdesivir at $\$ 53.34$ per vial, below rivals. Reuters. https://www.reuters.com/ article/us-health-coronavirus-cipla-idUSKBN2492Q3. Accessed 30 Sep 2020

16. Chandna H, Agrawal S. Rs 60,000 for a Rs 5,500 vial: how remdesivir black-market thrives as Covid cases rise. The Print. https ://theprint.in/health/rs-60000-for-a-rs-5500-vial-how-remdesivir -black-market-thrives-as-covid-cases-rise/468695/. Accessed 30 Sep 2020

17. US Committee on Finance. The pricing of Sovaldi. https://www. finance.senate.gov/imo/media/doc/3\%20The\%20Pricing $\% 20$ of\%20Sovaldi\%20(Section\%203).pdf . Accessed 25 Sep 2020. 